\title{
The evaluation of the operation of continuous monitoring system control of power quality at mining enterprises
}

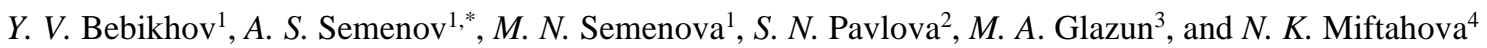 \\ ${ }^{1}$ North-Eastern Federal University n.a. M.K. Ammosov, Polytechnic Institute (branch) in Mirny, Mirny, Sakha (Yakutia), Russia \\ ${ }^{2}$ North-Eastern Federal University n.a. M.K. Ammosov, Yakutsk, Russia \\ ${ }^{3}$ Saint-Petersburg Mining University, St Petersburg, Russia \\ ${ }^{4}$ Kazan State Power Engineering University, Kazan, Russia
}

\begin{abstract}
In the paper, theoretical and experimental studies including measuring of the electricity quality indices at mining enterprises were made. The evaluation of the efficiency of the applied means of highharmonic compensation was fulfilled. The proposals to create the system for continuous monitoring of power quality indices were developed. Electrical devices of surface and underground complexes of mines connected to distribution networks $6 \mathrm{kV}$ and used in mining and processing of diamondiferous ores were considered as the research objects. The results of installation of the monitoring system of electric power quality indices at electric drives and frequency converters of some process units were studied. Technical and economic analysis was carried out, and the guidelines concerning the improvement of energy efficiency of frequency-controlled electric drives were formulated.
\end{abstract}

\section{Introduction}

Polytechnic Institute (branch) of the Ammosov NorthEastern Federal University in Mirny, in cooperation with the Joint Stock Company ALROSA (PJSC) and the National Research University conducted the research of power quality of the power supply system installed at one of the diamond mines of Yakutia in 2010-2012. The measurements of power quality indices were taken as the basis of the research carried out directly at one of the substations and cells of the mine. It is known [1] that power quality affects the operation of electrical equipment. When power quality is non-standard, electrical equipment exposed to electromagnetic interference functions improperly [2]. In this connection, service life and performance of equipment are reduced, thereby affecting the technological process [3]. The quality of electrical energy is characterized by power quality indices mostly standardized according to GOST 32144-2013 [4] (previously GOST 13109-97 [5]). The problem worsens in cases when electrical equipment liable to create such interference (due to its operation principle) is installed at the power supply system [6]. Frequency-controlled electric drives based on asynchronous motors and DC motors installed at the examined mine relate to similar equipment [7]. Interference created by them has a negative effect on the other equipment [8].

The power of electric drive systems used at the mine reaches tens of MW and constitutes the main share of the enterprise's load that determines the nature of the impact of higher harmonics on the power supply system as a whole [9]. One of the effective measures used to reduce higher harmonics generated by an electric drive to normalized values is the installation of filtercompensating devices [10]. Typically, such measures are developed at the stage of design of power supply system specifying the parameters of filter-compensating device according to the results of measurements of power quality indices [11]. Thus, preliminary calculations and their correction under operating conditions is the method showing the best results. The effectiveness of filtercompensating devices is monitored during their service life by periodic or continuous monitoring of power quality. The research of the mine's power supply system allowed to implement the method in operation in a full scale. It includes the following: taking measurements, making necessary calculations and conclusions concerning the effectiveness of using filtercompensating devices in the considered power supply system.

As a result of the research, the system for continuous monitoring of the quality indices of electrical energy at the installations of the mine was developed and implemented [12]. The continuous monitoring system was introduced at the skip lifting site and the crushing site of the technological stowing complex of mine. Several problems connected with inefficient power consumption were revealed already in the first year of its operation on the basis of gathered measurements [13]. According to the results of five years (2014-2018) operation the feasibility study and justification confirming the feasibility of introducing the system of

* Corresponding author: as.semenov@s-vfu.ru 
continuous monitoring of power quality at the underground mine sites were made.

The guidelines concerning the use of certain frequency-controlled electric drive systems at mining enterprises in order to reduce the energy intensity of production and increase the efficiency of electrical equipment operation were presented [14-19].

\section{Brief theoretical part}

In modern underground mining enterprises, the loads with non-linear characteristics are becoming more and more common. These include, first of all, various types of valve converters used to regulate the coordinates of an electric drive. The widespread use of valve converters is conditioned by high technical and economic indicators and operational advantages corresponding to modern requirements of technological processes and therefore become the main tool of controlled conversion of electrical energy into mechanical one. Among the most significant adverse features of valve converters worsening their electromagnetic compatibility with the adjacent power supply networks are the consumption of reactive power at the fundamental frequency and the distortion of voltage form accompanied by the generation of higher harmonics into a network.

Both of these features are conditioned by valve switching, but they have different mechanism of origin. Higher harmonics of voltage and current affect electrical equipment, automation systems, relay protection, remote control and communication negatively: additional losses in electrical machines, transformers and networks are noticed; it is difficult to compensate the reactive power using capacitor banks; the service life of insulation of electrical machines and apparatus is reduced; the accident rate in cable networks increases; the operation quality deteriorates, and sometimes failures in operation of relay protection, automation, remote control and communication systems occur.

Hence, the solution of the problem of electromagnetic compatibility is necessary and urgent.

Main objectives of measurements of power quality indices include: the detection of interference and their evaluation; registration of measured numerical characteristics in order to process and display the results; the evaluation of measured values of power quality indices for compliance with the established requirements; determination of interference sources; making commercial settlements between suppliers and consumers of electricity. To make measurements, it is necessary to determine the type of control, the point of measurements and the types of controlled power quality indices. Two types of power quality monitoring, periodic and permanent, can be distinguished depending on the duration of observations. The difference between continuous monitoring and periodic monitoring consists in the continuity of measurements in time and processing of results.

\section{Problem statement}

Currently, the important task for solving the issues of an effective use of electricity is the creation of the effective system of power quality control. The results of the system operation can influence the investment programs of companies greatly. In the process of quality control, the compliance of the values of power quality indices with the established standards is determined. Control is the first stage of quality monitoring determining current technical conditions and existing problems.

At present, the quality control of electrical energy at enterprises is periodic and short-term. It is mainly carried out during certification, periodic and some other types of tests in order to confirm the compliance with obligatory requirements. The results of short-term tests do not reflect the situation in the field of power quality sufficiently and reliably.

Long-term tests are required for continuous monitoring of power quality concerning some power quality indices. This applies primarily to the parameters of voltage dips and parameters of temporary overvoltages. The accumulation of measurement information characterizing these dynamic processes and its statistical processing should be carried out for one year. If this requirement concerning test duration is followed, the obtained statistical characteristics can be used to improve the contractual relationship between suppliers and consumers of electricity.

\section{The results of implementation of the monitoring system}

The block diagram of the measuring system made using measuring instruments and software "RESURS" is presented in [12]. The structure of automated information-measuring system of power quality control includes the following components: measuring components (measuring voltage and current transformers); complex components, measuring and computing complexes (meters of electricity quality indicators, software and hardware complexes for controlling the quality of electricity); connecting components (communication lines between instrument transformers and meters of power quality indices, GSM modems, equipment and Ethernet networks, concentrators-HUB); computing components (data servers, data collection stations and workstations equipped by system and application software).

The measurements were made in an interval of 1 second and great amount of data were obtained. To construct the average daily graphs with a minute interval of measurements, the method of processing and analyzing the results presented in $[4,5]$ is used. The most important graphical results of the monitoring system operation are presented below.

The following conclusions can be made from the analysis of the measurement results: the deviation value of phase and interfacial voltages (in Figure 1 and 3) exceeds the acceptable value of $5 \%$, but does not exceed the critical value equal to $10 \%$ of the nominal value; 
frequency deviations are within normal limits and do not exceed the acceptable $0.2 \mathrm{~Hz}$; the value of the power factor of the installations below 0.8 is not noticed (good indicator); the coefficient values of the sinusoidal distortion of phase and interphase voltages slightly exceed $3 \%$ and thus are observed within the acceptable values; the coefficients 23 and 25 of the harmonic components (in Figure 2) exceed the maximum acceptable values equal to $1.5 \%$ by $0.75 \%$ and $0.35 \%$, respectively, and make up $2.25 \%$ and $1.85 \%$, that exceeds the nominal acceptable value equal to $1 \%$ by 2.25 and 1.85 times respectively; the coefficients of 35 and 37 harmonic components (in Figure 2) exceed the maximum acceptable values of $1.15 \%$ and $1.10 \%$ by $0.8 \%$ and $0.65 \%$, respectively, and make up $1.95 \%$ and $1.75 \%$, that exceeds the nominal acceptable value of $0.75 \%$ by 2.6 and 2.3 times, respectively; coefficients of 35 and 37 harmonic components (in Figure 4) exceed the maximum acceptable values equal to $1.15 \%$ and $1.10 \%$ by $0.1 \%$ and $0.15 \%$, respectively, and make up approximately $1.25 \%$, which exceeds the nominal acceptable value equal to $0.75 \%$ by 1.6 times; current and voltage signals in dips and overvoltages have a highly distorted sinusoidal shape caused by unstable operation of electrical equipment in such modes.

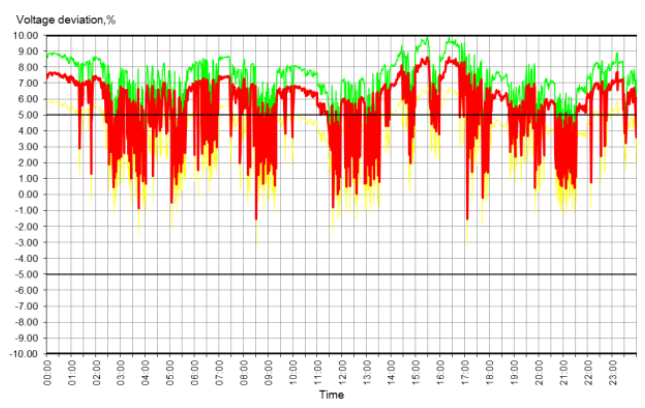

Fig. 1. The graph of voltage fluctuations of hoist installation.

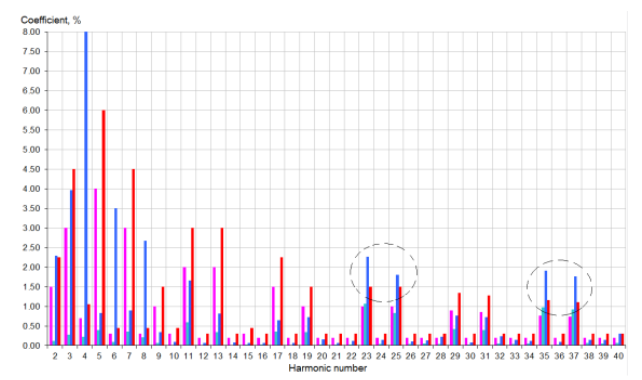

Fig. 2. The coefficients of the n-th harmonic components of the voltage of hoist installation.

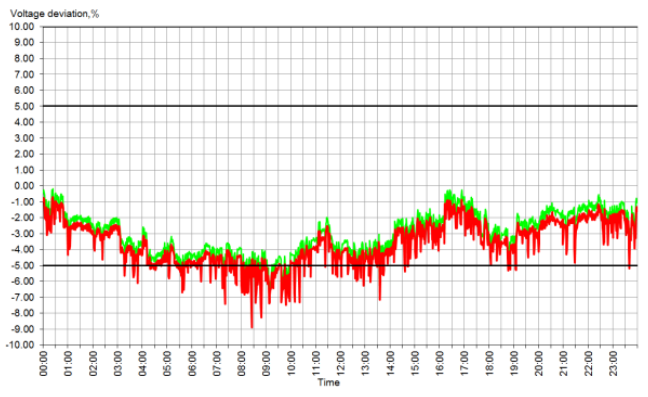

Fig. 3. The graph of voltage fluctuations of ball mill.

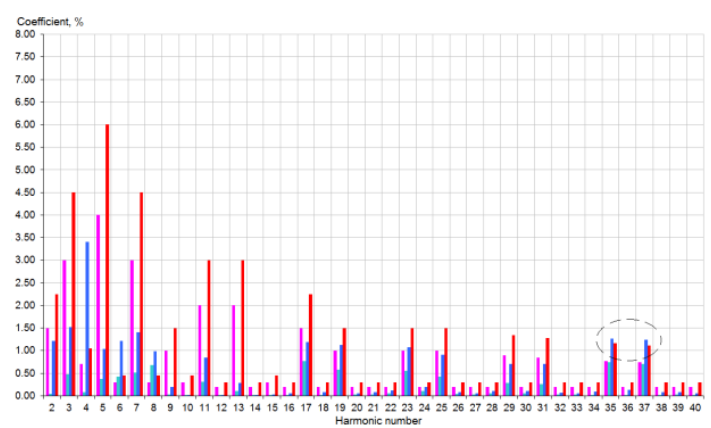

Fig. 4. The coefficients of the n-th harmonic components of the voltage of ball mill.

The results of measurements of power quality indices made at hoist installation of the skip shaft and at the ball mill of the technological stowing complex area of the mine were compared. The following conclusions can be driven: frequent overvoltages take place at skip hoist installation, sometimes reaching $10 \%$ of the nominal value in phase " $\mathrm{B}$ " whereas the shortage of voltage approaching $9 \%$ of the nominal value in phase " $\mathrm{C}$ " occur at the ball mill. Perhaps such data are explained by more distant location of the ball mill from the transformer substation, rather than the skip machine and incorrect choice of the power cable section; higher deviations of the n-th harmonic components are observed at the skip hoist installation, unlike the ball mill, in particular, 23, 25,35 and 37 . That is probably stipulated by the type of electric drive of the skip hoist installation (DC motor with a powerful converter having 12- pulse rectification circuit), whereas synchronous motor with a direct start acts as an electric drive at the ball mill.

\section{The results of technical and economic calculations}

The analysis of the measurement results of power consumption already in the first year at the hoist installation of a skip shaft and at the ball mill of the technological stowing site of the mine allowed determining one of the weak sections of the power system. The $350 \mathrm{~kW}$ synchronous motor installed at the ball mill is powered by a TM-1000 transformer. In accordance with GOST, this power line is provided by two transformers. The calculation based on the data of the implemented monitoring system showed a low load factor of the transformer, and, consequently, significant losses of electricity at the idling rate of the transformer.

To reduce idle rate losses and increase the load factor at the mine sites, the following solutions can be used: reducing the power of the transformers feeding the equipment at the site; the increasing the number of power consumers connected to the given transformer of the particular site. The losses of idle operation of two TM-1000 transformers were determined depending on the load factor of the transformers according to the procedure given in [20]. Each year (for five years) the power of equipment on transformers was intentionally increased by $20-25 \%$. Thus, the savings on the payment for electricity due to the reduction of idle rate losses of 
the transformer with the increase of its load factor can be calculated. The necessity of such increase was revealed during the monitoring of power quality using the implemented system. The calculation of the costs savings at the expense of the use of such technical measures is presented in Table 1 .

Table 1. The calculation of savings of electricity payments with the decrease of idle rate losses and with the increase of the load factor of the transformer.

\begin{tabular}{|c|c|c|c|c|c|c|}
\hline \multirow{2}{*}{$\mathrm{o}$} & Parameter name & \multicolumn{5}{|c|}{ Calculated interval in years } \\
\cline { 3 - 7 } & $\mathbf{2 0 1 4}$ & $\mathbf{2 0 1 5}$ & $\mathbf{2 0 1 6}$ & $\mathbf{2 0 1 7}$ & $\mathbf{2 0 1 8}$ \\
\hline 1 & $\begin{array}{c}\text { Transformer full } \\
\text { power, kVA }\end{array}$ & 2000 & 2000 & 2000 & 2000 & 2000 \\
\hline 2 & $\begin{array}{c}\text { Installed power } \\
\text { equipment, kW }\end{array}$ & 640 & 800 & 960 & 1200 & 1440 \\
\hline 3 & $\begin{array}{c}\text { Transformer load } \\
\text { factor }\end{array}$ & 0.32 & 0.4 & 0.48 & 0.6 & 0.72 \\
\hline 4 & $\begin{array}{c}\text { Work time per year, } \\
\text { hours }\end{array}$ & 5400 & 5400 & 5400 & 5400 & 5400 \\
\hline 5 & No-load losses, kW & 119.1 & 76.3 & 52.9 & 33.8 & 23.5 \\
\hline 6 & $\begin{array}{c}\text { The cost of 1 kWh } \\
\text { of electricity, rubles }\end{array}$ & 3.95 & 4.54 & 5.02 & 5.48 & 5.95 \\
\hline 7 & $\begin{array}{c}\text { The cost of no-load } \\
\text { loss, thousand } \\
\text { rubles }\end{array}$ & 2540 & 1870 & 1434 & 1000 & 755 \\
\hline
\end{tabular}

$$
\begin{gathered}
C_{\text {s.e. }}=\left(C_{\text {n.l. }}^{2014}-C_{n . l .}^{2015}\right)+\left(C_{n . l .}^{2014}-C_{n . l .}^{2016}\right)+ \\
+\left(C_{n . l .}^{2014}-C_{n . l .}^{2017}\right)+\left(C_{n . l .}^{2014}-C_{n . l .}^{2018}\right)=5101,
\end{gathered}
$$

where is $C_{\text {s.e. }}$ - the cost of saving electricity, thousand rubles; $C_{n . l .}^{20 X X}$ - the cost of no-load loss (in a certain year), thousand rubles.

The introduction of monitoring system of power quality at two facilities of mine (hoist installation of the skip shaft and the ball mill of the technological filling section) allowed to save 5101 thousand rubles for 5 years due to the decrease of idle rate losses and the increase of the load factor of transformers installed at the sites, that exceeds the expenses spent for the implementation of such power quality monitoring system in ten times

\section{Conclusions}

As a result of the accomplished work, information concerning power supply system of the mine was collected. Theoretical and experimental studies of power quality at the bus site were made. The calculated values were compared with the actual measurements obtained during the instrumental study of the parameters of power quality. It was revealed the necessity of the diagnostics of the 5th harmonic filter capacitors to check their integrity. It has been concluded that it is preferable to install active high-harmonic filters instead of passive filters at the installation of filter compensation devices at 1CSH-6-1T $6 \mathrm{kV}$ bus section (above-ground $6.3 \mathrm{kV}$ distributing device) because of the peculiarities of the operation modes of electrical receivers.
The methods of power quality control at mining enterprises were formulated. The concept of the continuous monitoring system of power quality was developed on the basis of the proposed methods. It was given the justification of the choice of the means of recording and monitoring the quality of electric energy. According to the results of the study, the system of continuous monitoring of power quality of mine objects was introduced: the electric drive of skip hoist installation and of the ball mill at the crushing site of the technological filling complex. The guidelines for energy service of mining enterprise the introduction of equipment and instruments to optimize power quality and improve energy efficiency of process equipment were developed.

The analysis of the operation of continuous monitoring system of power quality at the facilities of the underground mine was being carried out for one year and large discrepancies in the operation of power supply system were revealed. As a result of five years of monitoring the work of the implemented system, the feasibility study was made which allowed to solve not only a technical problem in the operation of electrical equipment, but also to obtain a large economic effect by saving energy costs spent on transformer losses.

It should be noted that all power consumers considered during the experiment were either frequencycontrolled electric drives or electric drives with DC motor, which are main electrical receivers affecting the quality of electrical energy of the supply network and leading to the distortion of the voltage curve, i.e. the appearance of a non-sinusoidal voltage and current curve, the deviation of the coefficient of harmonic components from the required rates. In this regard, the methods improving the effectiveness of the introduction of frequency-controlled electric drive systems at the specific technological installations should be developed at mining enterprises [21, 22].

This work was financially supported by Kazan State Power Engineering University.

\section{References}

[1] A.V. Agunov, T.S. Titova, V.A. Kruchek, Russian Electrical Engineering 87, 251 (2016)

[2] T.M. Isaeva, Glavnyy energetic 11, 32 (2016)

[3] N.M. Kuznetsov, A.N. Egorov, N.V. Egorov, Gornyi Zhurnal 7, 87 (2010)

[4] GOST 32144-2013 Electric Energy. Electromagnetic compatibility of technical equipment. Standards of quality of electrical energy in generalpurpose power supply systems (Moscow: FGUP Standartinform) 19 (2014)

[5] GOST 13109-97 Electric Energy. Electromagnetic compatibility of technical equipment. Standards of quality of electric energy in generalpurpose power supply systems (Moscow: FGUP Standartinform) 34 (2006) 
[6] V.N. Tulskiy, I.I. Kartashev, N.M. Kuznetsov, M.G. Simutkin, Kh.B. Nazirov, Gornyi Zhurnal 12, 52 (2012)

[7] A.M. Kostygov, A.V. Kychkin, S.A. Artemov, Russian Electrical Engineering 86, 667 (2015)

[8] D. Feng, M. Lu, J. Lan, L. Sun, IET Generation, Transmission \& Distribution 10, 3322 (2016)

[9] Y.V. Shevyrev, N.Y. Shevyreva, Gornyi Zhurnal 1, 66 (2019)

[10] V.N. Fashchilenko, S.N. Reshetnyak, Gornyi Zhurnal 7, 80 (2017)

[11] V.I. Mishin, R.N. Chuenko, V.V. Gavrilyuk, Russian Electrical Engineering 80, 444 (2009)

[12] N.M. Kuznetsov, A.S. Semenov, Yu.V. Bebikhov, A.V. Rybnikov, Gornyi Zhurnal 1, 23 (2014)

[13] A.S. Semenov, N.M. Kuznetsov, Measurement Techniques 57, 417 (2014)

[14] A.N. Shpiganovich, V.I. Zatsepina, A.A. Shpiganovich, V.M. Stepanov, EAI Endorsed Transactions on Energy Web 5, E10 (2018)

[15] E.I. Gracheva, R.R. Sadykov, R.R. Khusnutdinov, Proceedings of the higher educational institutions.Energy sector problems 20, 13 (2018)

[16] E.I. Gracheva, O.V. Naumov, Safety \& Reliability of Power Industry 11, 325 (2018)

[17] S.S. Kubrin, S.N. Reshetnyak, Gornyi Zhurnal 1, 87 (2016)

[18] E.I. Gracheva, O.V. Naumov, Journal of Engineering and Applied Sciences 11, 2934 (2016)

[19] A.I. Fedotov, E.I. Gracheva, E.A. Fedotov, N.V. Chernova, Journal of Engineering and Applied Sciences 11, 2939 (2016)

[20] O.V. Fedorov, A.S. Semenov, A.N. Egorov, V.M. Khubiyeva, Proceedings of the higher educational institutions. Energy sector problems 9-10, 91 (2016)

[21] A.N. Egorov, A.S. Semenov, Yu.V. Bebikhov, A.A. Sigaenko, International Journal of Energy for a Clean Environment 20,153 (2019)

[22] A.N. Egorov, A.S. Semenov, Ya.S. Kharitonov, O.V. Fedorov, Gornyi Zhurnal 2, 77 (2019) 